\title{
Early Rehabilitation of Distal Radius Fractures Stabilized by Volar Locking Plate: A Prospective Randomized Pilot Study
}

Stefan Quadlbauer, MD ${ }^{1,2,3}$ Christoph Pezzei, MD ${ }^{1}$ Josef Jurkowitsch, MD ${ }^{1}$ Brigitta Kolmayr, MSc ${ }^{4}$ Tina Keuchel, MD ${ }^{1}$ Daniel Simon ${ }^{5}$ Thomas Hausner, MD²,2,3 Martin Leixnering, MD ${ }^{1}$

${ }^{1}$ AUVA Trauma Hospital Lorenz Böhler - European Hand Trauma Center, Vienna, Austria

2 Ludwig Boltzmann Institute for Experimental und Clinical Traumatology, AUVA Research Center, Vienna, Austria

${ }^{3}$ Austrian Cluster for Tissue Regeneration, Vienna, Austria

${ }^{4}$ Department of Physiotherapy, AUVA Trauma Hospital Lorenz Böhler European Hand Trauma Center, Vienna, Austria

${ }^{5}$ Medical University of Vienna, Vienna, Austria

J Wrist Surg 2017;6:102-112.

\begin{abstract}
Address for correspondence Stefan Quadlbauer, MD, Department of Traumatology, AUVA Trauma Hospital Lorenz Böhler - European Hand Trauma Center, Donaueschingenstrasse 13, A-1200, Vienna, Austria (e-mail: stefan.quadlbauer@auva.at).
\end{abstract}

received

May 20, 2016

accepted after revision

June 30, 2016

published online

August 5, 2016
Background Distal radius fractures are very common and an increased incidence of $50 \%$ is estimated by 2030 . Therefore, both operative and postsurgical treatment remains pertinent. Main aim in treating intra-articular fractures is to restore the articular surface by internal fixation and early mobilization (EM).

Questions/Purposes The purpose of this study was to compare functional results between EM immediately after surgery and 5 weeks of immobilization (IM).

Patients and Methods In a randomized prospective study, 30 patients with an isolated distal radius fracture were treated by open reduction and internal fixation using a single volar locking plate excluding bone graft. Fifteen patients were randomized in the EM group and 15 in the IM group. At 6 weeks, 9 weeks, 3 months, 6 months, and 1 year postsurgery, range of motion, grip strength and X-rays were evaluated. Additionally, Quick Disability of the Arm, Shoulder and Hand (QuickDASH) questionnaire, PatientRated Wrist Evaluation (PRWE), modified Green O'Brien (Mayo) score, and pain according to the Visual Analog Scale score were analyzed.

Results Patients in the EM group had a significantly better range of motion in the sagittal plane, in grip strength up to 6 months, in the frontal plane up to 9 weeks, and in forearm rotation up to 6 weeks. Also QuickDASH and PRWE scores were better up to 6 weeks postsurgery. The Green O'Brien score differed significantly up to 1 year. At 1 year, 93\% "excellent" and "good" results in the Green O'Brien score with a mean QuickDASH of $5.98 \pm 10.94$ and PRWE score of $4.27 \pm 9.23$ were observed in the EM group. No differences regarding loss of reduction, pain, duration of physiotherapy, and sick leave were noted.

Conclusion EM of surgically treated distal radius fractures (without bone graft) is a safe method for postoperative aftercare and leads to an improved range of motion and grip strength at 6 months postsurgery compared with an IM of 5 weeks.

Level of Evidence This is a level Ib clinical study.

\section{Keywords}

- volar locking plate

- outcome
Copyright $\odot 2017$ by Thieme Medical Publishers, Inc., 333 Seventh Avenue, New York, NY 10001, USA. Tel: +1(212) 584-4662.
DOI http://dx.doi.org/ 10.1055/s-0036-1587317. ISSN 2163-3916. 
Distal radius fractures (DRFs) are the most common fractures of the upper extremities, particularly in osteoporotic patients. ${ }^{1}$ In 2000, Court-Brown and Caesar et al showed an incidence of 195 DRFs per 100,000 adults as published by the Edinburgh Royal Infirmary. Calculations show that white women aged 50 years are more prone to DRF by $15 \%$ than men of the same age who have only a $2 \%$ lifetime risk. ${ }^{2}$

The past decade shows a trend toward open reduction and internal fixation of DRF by volar locking plate and away from K-wire and external fixation. By volar plating, dorsally displaced fractures can be stabilized and the risk of extensor tendon irritation, compared with dorsal plating, is reduced. Additionally, several clinical trials have shown faster recovery of hand function with volar plating compared with k-wire or external fixation. ${ }^{3,4}$

As in other intra-articular fractures, the main therapeutic principles should be exact reconstruction of the articular surface, stable internal fixation, and early mobilization (EM). ${ }^{5,6}$ However, it is interesting that these principles are not applied in fractures of the wrist, although they occur frequently. ${ }^{7}$ Even today, there is no consensus about the best aftercare regime. Several studies on conservatively treated DRF suggest that shorter immobilization (IM) leads to quicker recovery in wrist function, without the increased risk of secondary displacement. ${ }^{8}$ In contrast, the guidelines of the American Academy of Orthopaedic Surgeons do not recommend early wrist mobilization on a routine basis after stable fixation ${ }^{9}$ and a different guideline proposes an IM depending on type of osteosynthesis and achieved stability. ${ }^{10}$

To our knowledge, only few studies exist comparing an early rehabilitation protocol with IM after volar plating of DRF. ${ }^{11}$

Main aim of this prospective randomized trial was to compare immediate mobilization (EM group) with 5-week IM (IM group) after volar plate fixation of DRF. The null hypothesis presupposed no difference between the groups in regard to range of motion 6 weeks, 9 weeks, 3 months, 6 months, and 1 year after surgery. Furthermore, we analyzed grip strength, wrist scores, pain level, length of sick leave and physiotherapy, complications, and radiological results.

\section{Patients and Methods}

Institutional review board approval was obtained for this prospective randomized trial. The study from December 2010 to September 2011 included 30 patients with DRF who were treated by open reduction and a volar angular stabilizing locking plate. Indications for surgery included a displaced DRF with a dorsal tilt more than 15 degrees, an intra-articular step of more than $1 \mathrm{~mm}$, or a radial shortening of more than $2 \mathrm{~mm}$ in the standard radiographs. Bone quality was not considered as a relevant factor in this study.

Inclusion criteria were as follows: (1) age 18 to 75 years, (2) isolated displaced DRF (A2-C3.2), (3) surgical procedure by open reduction and stabilization using only a volar angular stable locking plate, and (4) patients capable of giving consent. Exclusion criteria were as follows: (1) age under 18 or over 75 years; (2) open fractures; (3) pathological fractures; (4) C3.3 DRFs; (5) associated fractures of the distal ulna (except fractures of the processus styloideus ulnae); (6) other concomitant fractures, polytrauma; (7) additional stabilization of the distal radius (Screw, K-wire); (8) bilateral fractures; and (9) patients unable to comply with postoperative therapy.

\section{Randomization and Implementation}

A total of 30 patients who met the criteria and had signed the informed consent were randomly allocated into two groups: the EM or IM group. Using a block envelope randomization, three groups of 10 patients per group were formed. Ten sealed envelopes were handed out, containing five folded sheets with EM and five folded sheets with IM. A random person not involved or familiar with the study was chosen to select an arbitrary envelope. The envelope was opened after surgery; thus, the surgeon was blinded for the group choice of the patient during the operation.

\section{Blinding}

Owing to the design of the study, blinding was not possible in all aspects of the study. Surgeons and therapists, as care providers, were not blinded in respect to the treatment allocation, but they were unaware of the group allocation of the patient during surgery. Clinical examination was performed by an independent examiner, who was blinded to the method of treatment. The clinical and radiological outcome analyst (D.S.) was not a treating surgeon and also blinded to the group affiliation of the patient.

\section{Intervention}

\section{Surgical Procedure}

All procedures were performed under fluoroscopic assistance, and the standard volar-radial approach over the flexor carpi radialis tendon according to Henry was chosen. Reduction was achieved by temporary K-wires. No bone grafts were done. In all cases, APTUS 1.6 distal radius locking plate ( 2 fracture and 28 correction plates) was used (Medartis, Basel, Switzerland). Pronator quadratus repair were performed in all cases.

All patients received the same padded dressing immediately after wound closure as part of the postoperative dressing. On the first postoperative day, the dressing was changed for either a removable thermoplastic splint for 1 week or nonremovable plaster cast for 5 weeks. Directly postsurgery, all patients were advised to move shoulder, elbow, and fingers and perform light activities. Specific exercises were taught by specialist physiotherapist and occupational therapists.

\section{Early Mobilization Group}

Occupational therapists fitted all patients randomized into the EM group with a removable thermoplastic splint on day 1 after surgery, which was worn for 1 week. The patient was allowed to remove the splint along with the specific physiotherapy prescribed and do active exercises for the wrist and additionally exercises for the shoulder, elbow, and fingers. The patient was also encouraged to remove the splint occasionally at home in the first week for light daily activities. 
For the first 5 weeks, the patients in the EM group attended our outpatient physiotherapy clinic in the "EM group" for 30 minutes twice a week, and then subsequently were in the "hand group" for 45 minutes twice a week. Duration of physiotherapy units was determined on range of motion.

\section{Immobilization Group}

All patients randomized in the IM group received a nonremovable plaster cast for 5 weeks on the first postoperative day, and attended our outpatient physiotherapy department for 30 minutes twice a week for the first 5 weeks. Thereafter they performed twice weekly physiotherapy for the shoulder, elbow, wrist, and fingers in the "hand group" for 45 minutes. Duration of physiotherapy units was dependent on range of motion.

\section{Follow-up and Outcome Evaluation}

Follow-up examinations were performed 6 weeks, 9 weeks, 12 weeks, 6 months, and 1 year after surgery. At each examination, range of motion and grip strength (Jamar; Therapeutic Equipment, Clifton, NJ) of the injured and uninjured sides were measured. On the basis of extension/flexion, radial/ulnar deviation, supination/pronation, total range of motion in the sagittal, frontal plane, and forearm rotation were measured. Pain was assessed according the Visual Analog Scale (VAS, ranging from 0 [no pain] to 10 [worst possible pain]). Self-assessment by patients was registered on the Quick Disability of the Arm, Shoulder and Hand (QuickDASH) questionnaire, ${ }^{12}$ the Patient-rated Wrist Evaluation $(P R W E)^{13}$ and modified Green O'Brien (Mayo) score. ${ }^{14}$

Age, gender, and affected side were noted for statistical proposes. To calculate the duration of physiotherapy and sick leave, the first and last days of physiotherapy and sick leave were collected.
Each follow-up appointment included a standard radiological check in two planes (anteroposterior and lateral view). Additionally, the primary (pre-reduction) and immediate postoperative radiographs were checked for malalignment. Fractures were classified using the AO classification according to Müller et al. ${ }^{15}$ In the anteroposterior view, radial inclination was measured; ulnar variance was measured according to Gelberman; and in the lateral view, the angulation of the radial articular surface to radius shaft was measured. ${ }^{16}$ Fracture healing was defined as bone bridging of the radial, ulnar, and dorsal cortical aspects of the distal part of the radius. ${ }^{17}$

To test normal distribution of the numerical variables, Shapiro-Wilk test was used. The Mann-Whitney $U$-test was used to analyze the outcome, because the distribution of the majority of the results were not normal. Chi-square analysis was used for nominal variables. Threshold for statistical significance was $p<0.05$.

\section{Patient Characteristics}

Thirty patients who met the inclusion criteria were included in this prospective randomized trial, with a mean age of $53.80 \pm 14.06$ years. Of these, 26 patients were female and 4 were males. Two patients had to be excluded during the study, one patient because of a complex regional pain syndrome (CRPS; IM group) and another because of a primary onset of multiple sclerosis (IM group). Thus, the final analysis could be performed on 28 patients. Patients' demographic data are shown in - Table 1.

Eight right wrists and seven left wrists were affected in the EM group, while three right wrists and ten left wrists were affected in the IM group. In 53\% of the EM group and in $46 \%$ of the IM group, the dominant hand was injured. Mean duration of sick leave was $2.13 \pm 1.77$ months: $1.63 \pm 1.06$ months in the EM group and $2.71 \pm 2.29$ months in the IM group.

Table 1 Patients' demographic and fracture classified according to the AO classification

\begin{tabular}{|c|c|c|c|c|}
\hline & & \multicolumn{2}{|l|}{ Study group } & \multirow[t]{2}{*}{$p$-Value } \\
\hline & & $\begin{array}{l}\text { Early mobilization } \\
(n=15)\end{array}$ & $\begin{array}{l}\text { Immobilization } \\
(n=13)\end{array}$ & \\
\hline Mean age in years $( \pm S D)$ & & $49.13 \pm 15.41$ & $58.77 \pm 12.06$ & n.s. \\
\hline Mean duration sick leave in months ( \pm SD) & & $1.63 \pm 1.06$ & $2.71 \pm 2.29$ & n.s. \\
\hline Mean duration physiotherapy in months ( \pm SD) & & $2.73 \pm 1.39$ & $4.23 \pm 2.59$ & n.s. \\
\hline Gender & $\mathrm{F} / \mathrm{M}$ & $13 / 2$ & $11 / 2$ & n.s. \\
\hline Injured hand & $R / L$ & $8 / 7$ & $3 / 10$ & n.s. \\
\hline Dominant/Nondominant hand & $\mathrm{D} / \mathrm{N}$ & $8 / 7$ & $6 / 7$ & n.s. \\
\hline Ability to work & $A / I$ & $8 / 7$ & $7 / 6$ & n.s. \\
\hline Plate removal & $\mathrm{J} / \mathrm{N}$ & $2 / 13$ & $3 / 10$ & n.s. \\
\hline \multirow[t]{5}{*}{ AO classification } & $\mathrm{A} 2$ & 1 & 0 & \multirow[t]{5}{*}{ n.s. } \\
\hline & B3 & 1 & 0 & \\
\hline & C1 & 5 & 5 & \\
\hline & $C 2$ & 4 & 2 & \\
\hline & C3 & 4 & 6 & \\
\hline
\end{tabular}

Abbreviations: F, female; M, male; R, right; L, left; D, dominant; N, nondominant hand; NS, nonsignificant; w, working; I, inactive; J, yes; N, no. 
Overall, patients underwent $3.43 \pm 2.13$ months of physiotherapy (EM: $2.73 \pm 1.39$; IM: $4.23 \pm 2.69$ months). No significant differences between the groups in respect to age, ability to work, affected hand, dominant hand, frequency of plate removal, and AO classification $(p>0.05)$ were found. In five cases, a plate removal was necessary due to patient discomfort with the implant.

\section{Results}

\section{Clinical Results}

In the final follow-up after 1 year, mean value for pain was $0.39 \pm 1.07$ (EM: $0.40 \pm 1.06$; IM: $0.38 \pm 1.12$ ) which indicates a low pain level. There was no significant difference in pain at any follow-up between the groups ( $p>0.05$ ).

Functional outcome for each postoperative period is presented in - Table 2. Range of motion in the sagittal plane showed significantly better results in the EM group up to 6 months after surgery $(p=0.03)$. Extension also showed significantly better results in the EM group up to 6 weeks and flexion up to 9 weeks postsurgery. In the frontal plane, the EM group had significantly better results up to 9 weeks postsurgery $(p=0.04)$. For the forearm rotation, significantly better ranges up to 6 weeks postsurgery ( $p=0.03$ ) could be reported. Course of range of motion in extension/flexion, supination/pronation, and radial/ ulnar deviation is shown in - Fig. 1. The EM group showed a significantly better grip strength up to 6 months $(p=0.045)$. Course of grip strength is shown in - Fig. 2.

Compared with the uninjured side, patients in the EM group reached significantly better results in the radial-/ulnar deviation up to the half-year follow-up ( $p=0.01$ ), except for the 9-week follow-up $(p=0.06)$. In the frontal plane and forearm rotation, significant differences between the groups showed up to 6 weeks ( $p=0.004 ; p=0.02$ ). Grip strength was significantly better in the EM group up to 1 year compared with the uninjured side $(p=0.02)$.

Table 2 Mean functional outcome ( \pm SD) of injured side, mean difference $( \pm S D)$ and percentage of uninjured side (\%) depending on the follow-up point

\begin{tabular}{|c|c|c|c|c|c|}
\hline & \multicolumn{4}{|l|}{ Study group } & \multirow[t]{3}{*}{ p-Value } \\
\hline & \multicolumn{2}{|l|}{ Early mobilization } & \multicolumn{2}{|l|}{ Immobilization } & \\
\hline & Injured side ${ }^{a}$ & $\begin{array}{l}\text { Difference uninjured } \\
\text { side }(\%)^{\mathrm{a}}\end{array}$ & Injured side ${ }^{a}$ & $\begin{array}{l}\text { Difference uninjured } \\
\text { side (\%) }\end{array}$ & \\
\hline \multicolumn{6}{|l|}{6 wk } \\
\hline Extension (degree) & $45.33 \pm 8.76$ & $24.66 \pm 12.32(66)$ & $20.77 \pm 11.88$ & $46.54 \pm 12.31(30)$ & $<0.001^{\mathrm{b}} ;<0.001^{\mathrm{b}}$ \\
\hline Flexion (degree) & $44.00 \pm 11.37$ & $31.33 \pm 11.25(59)$ & $23.46 \pm 8.51$ & $48.85 \pm 9.61(32)$ & $<0.001^{\mathrm{b}} ;<0.001^{\mathrm{b}}$ \\
\hline Range of motion sagittal plane (degree) & $89.33 \pm 17.92$ & $57.00 \pm 18.97(61)$ & $44.23 \pm 17.66$ & $96.15 \pm 20.22(31)$ & $<0.001^{\mathrm{b}} ;<0.001^{\mathrm{b}}$ \\
\hline Supination (degree) & $57.00 \pm 22.27$ & $25.67 \pm 25.20(70)$ & $43.85 \pm 15.02$ & $37.31 \pm 13.63(54)$ & $0.07 ; 0.07$ \\
\hline Pronation (degree) & $61.67 \pm 13.97$ & $20.67 \pm 16.46(76)$ & $51.15 \pm 13.56$ & $34.23 \pm 12.89(60)$ & $0.04^{\mathrm{b}} ; 0.02^{\mathrm{b}}$ \\
\hline Range of motion forearm rotation (degree) & $118.67 \pm 33.19$ & $46.67 \pm 36.63(72)$ & $95.00 \pm 20.92$ & $71.54 \pm 20.76(57)$ & $0.03^{\mathrm{b}} ; 0.02^{\mathrm{b}}$ \\
\hline Radial deviation (degree) & $15.00 \pm 4.63$ & $4.67 \pm 3.52(76)$ & $10.00 \pm 4.56$ & $11.54 \pm 6.58(48)$ & $0.02^{\mathrm{b}} ; 0.003^{\mathrm{b}}$ \\
\hline Ulnar deviation (degree) & $27.67 \pm 8.21$ & $9.33 \pm 8.84(76)$ & $14.62 \pm 8.53$ & $18.85 \pm 10.03(45)$ & $<0001^{\mathrm{b}} ; 0.02^{\mathrm{b}}$ \\
\hline Range of motion frontal plane (degree) & $42.67 \pm 11.48$ & $14.00 \pm 9.67(75)$ & $25.38 \pm 12.16$ & $28.46 \pm 12.97(47)$ & $0.001^{\mathrm{b}} ; 0.004^{\mathrm{b}}$ \\
\hline Grip strength $(\mathrm{kg})$ & $14.46 \pm 9.18$ & $13.19 \pm 8.62(52)$ & $4.56 \pm 3.92$ & $24.00 \pm 8.87(15)$ & $<0.001^{\mathrm{b}} ; 0.001^{\mathrm{b}}$ \\
\hline QuickDASH score & $31.29 \pm 17.89$ & & $54.02 \pm 10.46$ & & $0.002^{\mathrm{b}}$ \\
\hline Green O'Brien score & $64.33 \pm 12.66$ & & $48.85 \pm 6.50$ & & $0.001^{\mathrm{b}}$ \\
\hline PRWE score & $36.13 \pm 12.87$ & & $49.35 \pm 14.60$ & & $0.02^{\mathrm{b}}$ \\
\hline VAS & $1.54 \pm 1.18$ & & $2.24 \pm 1.96$ & & 0.47 \\
\hline \multicolumn{6}{|l|}{9 wk } \\
\hline Extension (degree) & $54.67 \pm 9.90$ & $15.33 \pm 11.57(79)$ & $43.85 \pm 17.46$ & $23.46 \pm 16.38(65)$ & $0.05 ; 0.13$ \\
\hline Flexion (degree) & $52.67 \pm 9.04$ & $22.67 \pm 11.93(71)$ & $40.38 \pm 11.45$ & $31.92 \pm 11.82(56)$ & $0.01^{\mathrm{b}} ; 0.06$ \\
\hline Range of motion sagittal plane (degree) & $106.33 \pm 15.64$ & $40.00 \pm 15.70(73)$ & $84.23 \pm 26.60$ & $56.15 \pm 25.91(60)$ & $0.01^{\mathrm{b}} ; 0.06$ \\
\hline Supination (degree) & $68.33 \pm 18.68$ & $14.33 \pm 19.90(84)$ & $64.23 \pm 15.25$ & $16.92 \pm 13.93(79)$ & $0.44 ; 0.27$ \\
\hline Pronation (degree) & $72.00 \pm 9.22$ & $10.33 \pm 11.41(88)$ & $66.46 \pm 17.38$ & $18.92 \pm 15.47(78)$ & $0.32 ; 0.08$ \\
\hline Range of motion forearm rotation (degree) & $140.33 \pm 25.88$ & $25.67 \pm 27.51(85)$ & $130.69 \pm 29.95$ & $35.85 \pm 27.95(78)$ & 0.36 .0 .14 \\
\hline Radial deviation (degree) & $17.33 \pm 4.17$ & $2.33 \pm 3.72(88)$ & $16.15 \pm 3.63$ & $5.38 \pm 5.94(78)$ & $0.36 ; 0.25$ \\
\hline Ulnar deviation (degree) & $30.33 \pm 5.50$ & $6.67 \pm 6.17(83)$ & $23.85 \pm 5.83$ & $9.62 \pm 8.77(74)$ & $0.01^{\mathrm{b}} ; 0.44$ \\
\hline Range of motion frontal plane (degree) & $47.00 \pm 6.49$ & $9.00 \pm 7.43(84)$ & $40.00 \pm 8.66$ & $13.85 \pm 11.21(76)$ & $0.04^{\mathrm{b}} ; 0.36$ \\
\hline Grip strength $(\mathrm{kg})$ & $20.06 \pm 7.56$ & $7.59 \pm 6.67(74)$ & $12.28 \pm 8.35$ & $16.28 \pm 6.80(41)$ & $0.01^{\mathrm{b}} ; 0.003^{\mathrm{b}}$ \\
\hline QuickDASH score & $20.20 \pm 14.29$ & & $29.19 \pm 14.55$ & & 0.11 \\
\hline Green O'Brien score & $73.67 \pm 11.41$ & & $60.77 \pm 10.58$ & & $0.01^{\mathrm{b}}$ \\
\hline PRWE score & $24.27 \pm 14.87$ & & $27.54 \pm 13.88$ & & 0.46 \\
\hline VAS & $1.11 \pm 0.93$ & & $1.6 \pm 1.6$ & & 0.51 \\
\hline
\end{tabular}


106 Early Rehabilitation of Distal Radius Fractures Stabilized by Volar Locking Plate Quadlbauer et al.

Table 2 (Continued)

\begin{tabular}{|c|c|c|c|c|c|}
\hline & \multicolumn{4}{|l|}{ Study group } & \multirow[t]{3}{*}{$p$-Value } \\
\hline & \multicolumn{2}{|c|}{ Early mobilization } & \multicolumn{2}{|l|}{ Immobilization } & \\
\hline & Injured side $^{a}$ & $\begin{array}{l}\text { Difference uninjured } \\
\text { side }(\%)^{\mathrm{a}}\end{array}$ & Injured side ${ }^{a}$ & $\begin{array}{l}\text { Difference uninjured } \\
\text { side (\%) }\end{array}$ & \\
\hline \multicolumn{6}{|l|}{$3 \mathrm{mo}$} \\
\hline Extension (degree) & $60.33 \pm 10.26$ & $9.67 \pm 9.54(87)$ & $50.00 \pm 17.56$ & $17.31 \pm 17.03(75)$ & $0.10 ; 0.16$ \\
\hline Flexion (degree) & $59.33 \pm 11.48$ & $16.00 \pm 11.21(79)$ & $50.39 \pm 12.16$ & $21.92 \pm 10.32(70)$ & $0.07 ; 0.11$ \\
\hline Range of motion sagittal plane (degree) & $119.67 \pm 19.41$ & $26.67 \pm 16.97(82)$ & $100.38 \pm 26.81$ & $40.00 \pm 24.92(72)$ & $0.046^{\mathrm{b}} ; 0.046^{\mathrm{b}}$ \\
\hline Supination (degree) & $73.67 \pm 15.64$ & $9.00 \pm 16.71(90)$ & $70.38 \pm 17.61$ & $10.77 \pm 16.44(87)$ & $0.65 ; 0.36$ \\
\hline Pronation (degree) & $77.00 \pm 5.92$ & $5.33 \pm 7.43(94)$ & $75.31 \pm 13.37$ & $10.08 \pm 10.53(88)$ & $0.93 ; 0.13$ \\
\hline Range of motion forearm rotation (degree) & $150.67 \pm 19.90$ & $14.67 \pm 20.91(91)$ & $145.69 \pm 29.15$ & $20.85 \pm 26.22(87)$ & $0.72 ; 0.20$ \\
\hline Radial deviation (degree) & $18.67 \pm 2.97$ & $1.00 \pm 2.80(96)$ & $18.84 \pm 2.19$ & $2.69 \pm 3.88(90)$ & $0.96 ; 0.39$ \\
\hline Ulnar deviation (degree) & $31.67 \pm 4.88$ & $5.33 \pm 5.82(87)$ & $27.31 \pm 5.99$ & $6.15 \pm 8.70(84)$ & $0.14 ; 0.96$ \\
\hline Range of Motion Frontal Plane (degree) & $50.33 \pm 5.82$ & $6.33 \pm 6.67(90)$ & $46.15 \pm 6.50$ & $7.69 \pm 9.27(87)$ & $0.22 ; 0.96$ \\
\hline Grip strength $(\mathrm{kg})$ & $22.73 \pm 7.58$ & $4.92 \pm 4.64(83)$ & $16.29 \pm 9.73$ & $12.26 \pm 7.25(56)$ & $0.03^{\mathrm{b}} ; 0.01^{\mathrm{b}}$ \\
\hline QuickDASH score & $11.28 \pm 11.49$ & & $19.11 \pm 14.53$ & & 0.08 \\
\hline Green O'Brien score & $83.67 \pm 10.26$ & & $68.85 \pm 9.39$ & & $0.001^{\mathrm{b}}$ \\
\hline PRWE score & $11.57 \pm 9.19$ & & $16.38 \pm 14.95$ & & 0.45 \\
\hline VAS & $0.60 \pm 0.99$ & & $0.88 \pm 0.95$ & & 0.34 \\
\hline \multicolumn{6}{|l|}{$6 \mathrm{mo}$} \\
\hline Extension (degree) & $69.67 \pm 9.72$ & $0.33 \pm 3.52(100)$ & $58.85 \pm 15.96$ & $8.46 \pm 13.13(87)$ & $0.13 ; 0.03$ \\
\hline Flexion (degree) & $72.33 \pm 11.32$ & $3.00 \pm 7.74(96)$ & $58.85 \pm 12.27$ & $13.46 \pm 11.07(82)$ & $0.01 ; 0.02$ \\
\hline Range of motion sagittal plane (degree) & $143.33 \pm 18.87$ & $3.00 \pm 9.41(98)$ & $119.62 \pm 30.17$ & $20.77 \pm 24.57(85)$ & $0.03^{\mathrm{b}} ; 0.01^{\mathrm{b}}$ \\
\hline Supination (degree) & $83.67 \pm 7.67$ & $1.00 \pm 8.49(100)$ & $75.39 \pm 12.66$ & $5.77 \pm 9.54(93)$ & $0.09 ; 0.16$ \\
\hline Pronation (degree) & $81.67 \pm 5.88$ & $0.67 \pm 2.58(99)$ & $80.77 \pm 7.60$ & $4.62 \pm 5.19(95)$ & $0.82 ; 0.08$ \\
\hline Range of motion forearm rotation (degree) & $166.67 \pm 11.75$ & $1.33 \pm 9.90(100)$ & $154.62 \pm 21.45$ & $11.92 \pm 17.26(93)$ & $0.25 ; 0.02^{b}$ \\
\hline Radial deviation (degree) & $19.67 \pm 2.29$ & $0.00 \pm 1.89(100)$ & $20.77 \pm 4.00$ & $0.77 \pm 2.77(97)$ & $0.59 ; 0.75$ \\
\hline Ulnar deviation (degree) & $35.67 \pm 5.30$ & $1.33 \pm 3.99(97)$ & $29.23 \pm 3.44$ & $4.23 \pm 6.07(90)$ & $0.004^{\mathrm{b}} ; 0.25$ \\
\hline Range of motion frontal plane (degree) & $55.33 \pm 5.82$ & $1.33 \pm 4.42(98)$ & $50.77 \pm 7.03$ & $3.08 \pm 5.22(95)$ & $0.11 ; 0.47$ \\
\hline Grip strength (kg) & $26.96 \pm 7.09$ & $0.69 \pm 3.98(100)$ & $20.98 \pm 10.84$ & $7.58 \pm 6.36(72)$ & $0.045^{\mathrm{b}} ; 0.003^{\mathrm{b}}$ \\
\hline QuickDASH score & $4.88 \pm 6.76$ & & $11.46 \pm 11.70$ & & 0.1 \\
\hline Green O'Brien score & $90.67 \pm 7.29$ & & $75.77 \pm 10.96$ & & $0.001^{\mathrm{b}}$ \\
\hline PRWE score & $4.22 \pm 5.26$ & & $10.23 \pm 9.93$ & & 0.1 \\
\hline VAS & $0.13 \pm 0.52$ & & $0.25 \pm 0.47$ & & 0.272 \\
\hline \multicolumn{6}{|l|}{$1 \mathrm{y}$} \\
\hline Extension (degree) & $68.67 \pm 10.86$ & $1.33 \pm 5.81(99)$ & $63.46 \pm 14.05$ & $3.85 \pm 11.02(95)$ & $0.39 ; 0.65$ \\
\hline Flexion (degree) & $74.00 \pm 10.04$ & $1.33 \pm 4.81(98)$ & $67.31 \pm 11.11$ & $5.00 \pm 7.64(93)$ & 0.12 .0 .13 \\
\hline Range of motion sagittal plane (degree) & $144.33 \pm 16.57$ & $2.00 \pm 4.55(99)$ & $133.08 \pm 26.58$ & $7.31 \pm 18.44(95)$ & $0.20 ; 0.14$ \\
\hline Supination (degree) & $82.00 \pm 11.46$ & $0.67 \pm 2.58(99)$ & $79.23 \pm 11.88$ & $1.92 \pm 8.55(98)$ & $0.56 ; 0.89$ \\
\hline Pronation (degree) & $82.00 \pm 5.92$ & $0.33 \pm 1.29(100)$ & $82.31 \pm 9.27$ & $3.08 \pm 6.30(96)$ & $0.75 ; 024$ \\
\hline Range of motion forearm rotation (degree) & $164.33 \pm 12.66$ & $1.00 \pm 2.80(99)$ & $161.54 \pm 18.64$ & $5.00 \pm 13.23(97)$ & $0.93 ; 0.53$ \\
\hline Radial deviation (degree) & $19.33 \pm 3.72$ & $0.33 \pm 1.29(98)$ & $20.39 \pm 4.31$ & $1.15 \pm 3.00(95)$ & $0.75 ; 0.68$ \\
\hline Ulnar deviation (degree) & $35.00 \pm 6.55$ & $2.00 \pm 4.55(95)$ & $30.00 \pm 4.56$ & $3.46 \pm 6.58(92)$ & $0.03 ; 0.79$ \\
\hline Range of motion frontal plane (degree) & $54.33 \pm 9.04$ & $2.33 \pm 5.30(96)$ & $51.15 \pm 7.95$ & $2.69 \pm 6.65(96)$ & $0.27 ; 0.93$ \\
\hline Grip strength $(\mathrm{kg})$ & $27.99 \pm 8.03$ & $0.34 \pm 2.73(100)$ & $24.45 \pm 11.71$ & $4.10 \pm 5.18(83)$ & $0.21 ; 0.02^{b}$ \\
\hline QuickDASH score & $5.98 \pm 10.94$ & & $5.03 \pm 6.45$ & & 0.7 \\
\hline Green O'Brien score & $97.00 \pm 5.92$ & & $87.31 \pm 9.92$ & & $0.002^{\mathrm{b}}$ \\
\hline PRWE score & $4.27 \pm 9.23$ & & $4.65 \pm 5.76$ & & 0.35 \\
\hline VAS & $0.40 \pm 1.06$ & & $0.38 \pm 1.12$ & & 0.88 \\
\hline
\end{tabular}

Note: $p$-Values compare differences between early mobilization and immobilization group. First values account differences between the injured sides, second values express the differences between the injured to the uninjured side (uninjured side-injured side) between the groups.

${ }^{a}$ Values are given as mean and standard deviation.

bValues significant by a threshold of $p<0.05$. 

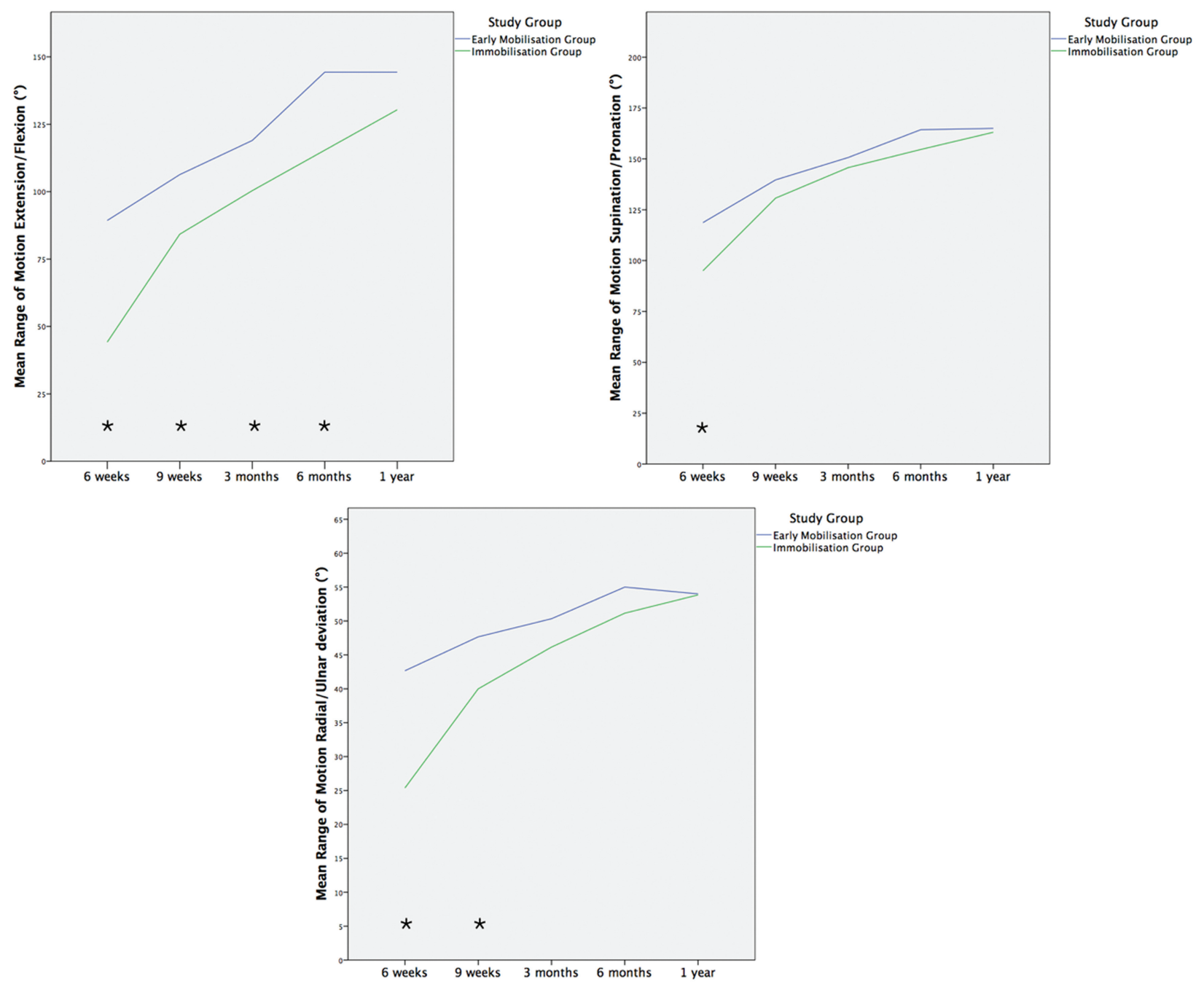

Fig. 1 Mean range of motion in extension/flexion, supination/pronation, and radial/ulnar deviation at each follow-up investigation. Values are given as mean at each follow-up investigation. "Values significant by a threshold of $p<0.05$.

All patients in the EM group had regained full range of motion in all planes including grip strength at 6 months after surgery.

QuickDASH and PRWE score showed significantly better results in the EM group up to 6 weeks postsurgery $(p=0.002 ; p=0.02)$. According to the Green O'Brien score, there were fifteen "excellent," eight "good," four "fair," and one "poor" results 1 year postsurgery. In the EM group, there were twelve "excellent," two "good," and one "fair," and in the IM group, three "excellent," six "good," three "fair," and one "poor" results. Modified Green O'Brien score showed significantly better results for the EM group up to 1-year postsurgery between the groups $(p=0.002)$. Overall in the modified Green O'Brien score, an "excellent" (97.00 \pm 5.92 points) result for the EM group and "good" (87.31 \pm 9.92 points) result for the IM group at 1 year were observed. Course of QuickDASH score, PRWE score, and modified Green O'Brien score is shown in -Fig. 3. One patient example is given in -Fig. 4.

\section{Radiological Results}

All fractures healed within 6 months after surgery. Detailed radiological outcome analysis is presented in - Table 3 . No significant differences could be found between the groups regarding palmar tilt, radial inclination, and ulnar variance from the radiographs at the last follow-up. There was also no significant difference between the groups in loss of reduction. No loss of reduction was detected in either group that would have required secondary surgical intervention.

\section{Complications}

Two patients had to be excluded during the study: one because of a CRPS (IM group) and the other due to primary onset of multiple sclerosis (IM group). In total, two complications occurred (6.9\%). One case of CRPS and one case of extensor pollicis longus rupture (EM group). There were no significant differences in relation to complication rates between the two groups.

\section{Discussion}

DRFs are the most common fractures of the human skeleton. ${ }^{18}$ Due to a growing population in the industrial countries with an increased life expectancy, an increase in incidence of 


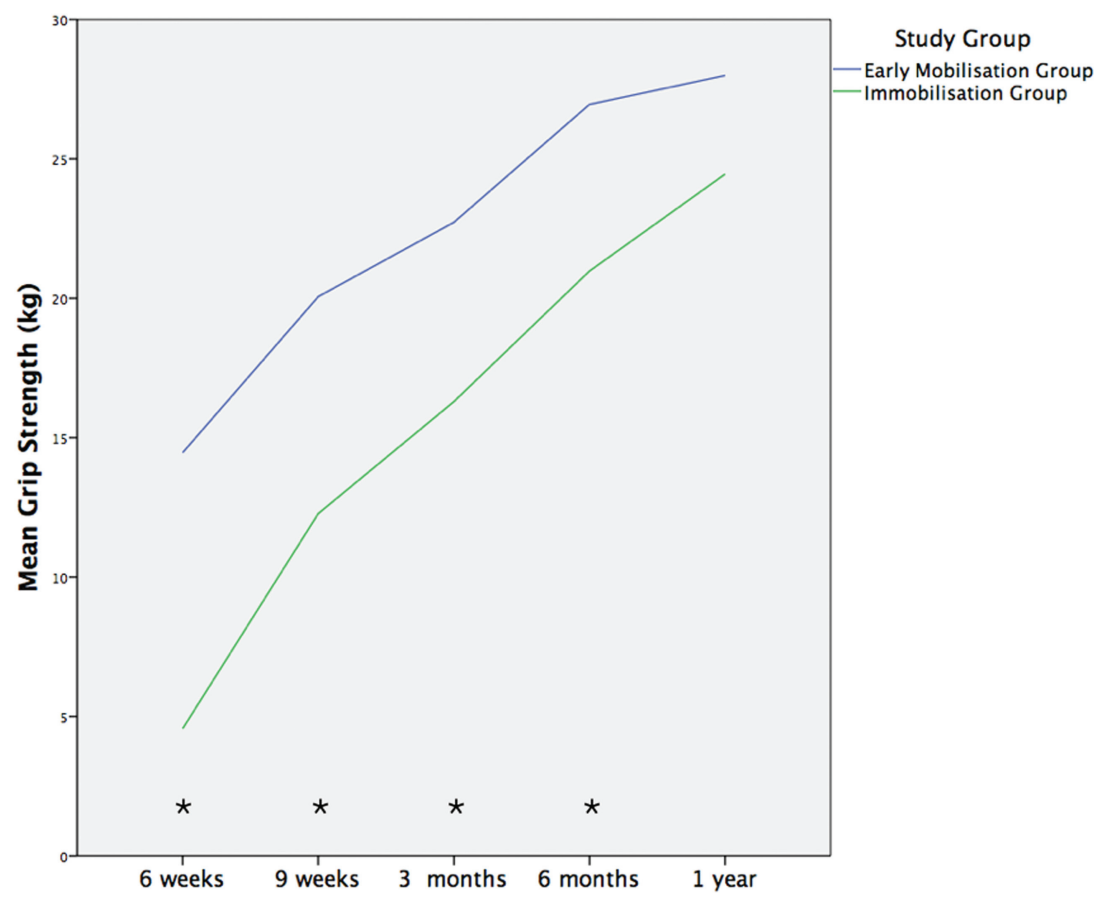

Fig. 2 Mean grip strength at each follow-up investigation. Values are given as mean at each follow-up investigation. ${ }^{*}$ Values significant by a threshold of $p<0.05$.

DRF of $50 \%$ is expected by $2030 .^{19}$ There are two peaks in prevalence of DRF, the first at age of 10 years and the second over the age of 60 years. ${ }^{20}$ Especially in the elderly population, DRF is very often associated with poorer bone quality and osteoporosis. ${ }^{21}$

The goal of surgically treated DRF should be anatomical reconstruction of the articular surface, stable fixation, and EM of the wrist and forearm. ${ }^{22}$ As early as 1814 , Colles warned his colleagues about prolonged wrist IM, which could lead to potential disabilities. ${ }^{23}$ Also the first 2 months of recovery significantly influence the final functional outcome. ${ }^{24}$ In addition, EM and axial load within 3 weeks after surgery has been shown to have a significant positive impact on bone healing in long bone fractures. ${ }^{25}$ Wrist movements in daily life activities cause an axial load pressure to the wrist joint by $100 \mathrm{~N}$. In contrast, active digital flexion leads to an axial load by $250 \mathrm{~N}$ to the wrist. Therefore, splinting and immobilizing of the wrist will not prevent fracture re-displacement if simultaneous active digital movement is allowed. ${ }^{26}$ Further, EM of the wrist allows the multiple chondral fragments to be modeled into the articular surface by active moving of the scaphoid and lunate. ${ }^{27}$ Biomechanical studies have shown that fixation of DRFs with volar locking plates provide a fivetime higher stability than forces caused by active finger movement. ${ }^{28,29}$ Therefore, open reduction and internal stabilization has become increasingly popular in the past decade to enable functional treatment in these injuries. ${ }^{3,4}$

Previous literature has described the functional treatment of operatively stabilized DRF in biomechanical studies, but only a few clinical studies are available. The literature widely accepts open reduction and internal fixation for treating DRFs, yet still no consensus for the optimal postoperative regime has been found to date. A recent Cochrane Database Review performed in 2015 by Handoll and Elliott ${ }^{30}$ on rehabilitation for DRFs in adults stated, as in 2006, ${ }^{31}$ that there is insufficient evidence in effectiveness in various rehabilitation protocols. Therefore, it is not surprising that only few studies report functional results after EM in case series and only one prospective randomized trial compared functional outcome of early postoperative mobilization with IM after DRF.

Koh et al performed a biomechanical study on fresh-frozen cadaver radii and simulated a postoperative regime of 1 -week IM and 5-week EM. The applied load on the distal radius simulated activities of daily living. They showed that all plating systems used provided enough stability for an EM protocol. ${ }^{22}$

Chung et $\mathrm{al}^{32}$ treated 161 patients with volar locking plates and EM. Patients were immobilized for 1 week and then commenced structured physiotherapy once a week for 6 weeks, with a removable splint for 6 weeks in situ. Our results at 6 months and 1 year were in total better in extension as well as flexion and up to 6 months in pronation and supination. Grip strength was even better up to 1 year after surgery.

Osada et $\mathrm{al}^{26}$ treated 49 DRFs functionally, immediately postsurgery without any IM. The authors encouraged the patients to do light daily activities using the hand. Weight lifting was allowed using less than $0.4 \mathrm{~kg}$ until fracture healing. At 1 year, they showed 48 (98\%) "excellent" and "good" results and only 1 (2\%) fair result in the modified Green O'Brien score with a mean DASH score of 6. Our results were similar to those reported in this study (14 [93\%] "excellent" and "good" and one [7\%] fair result with a mean QuickDASH by 6), but recovery of grip strength was better at 3 and 6 months postsurgery. Similar to our study, their $\mathrm{X}$-ray results also showed no significant loss of reduction. 

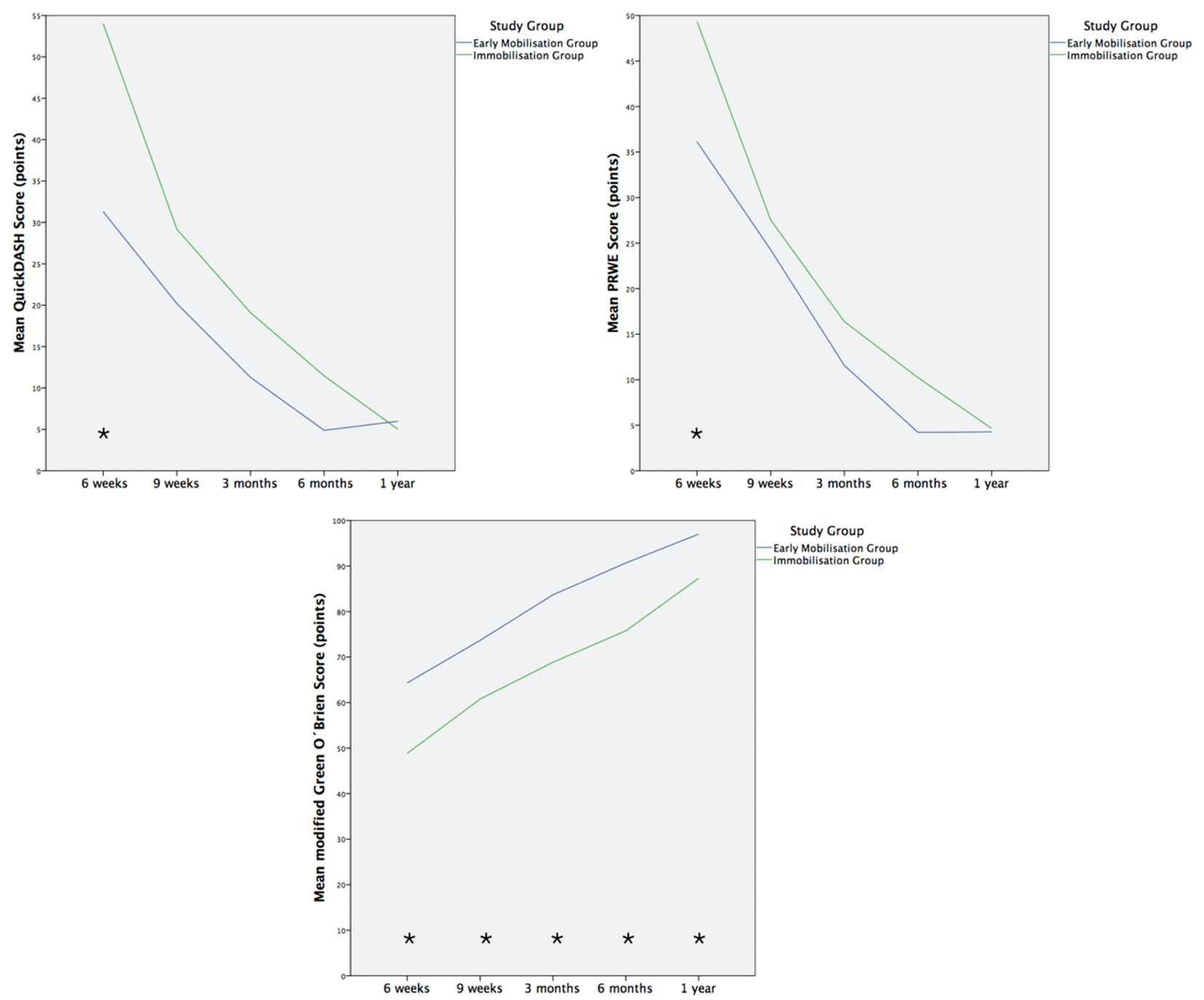

Fig. 3 Mean QuickDASH score, PRWE score, and modified Green O'Brien score at each follow-up investigation. Values are given as mean at each follow-up investigation. *Values significant by a threshold of $p<0.05$.

However, in this study, the patients performed no controlled physiotherapy. They were only assigned to physiotherapy after 21 days, if range of motion of the injured side was less than $50 \%$ compared with the uninjured side.

Lozano-Calderón et al ${ }^{11}$ performed a prospective randomized trial which compared EM with IM. They were not able to show significant differences between EM within 2 weeks and IM for 6 weeks, 3 and 6 months postsurgery in range of motion, grip strength, and in scores and radiographs. In our study, we were able to show significantly better results in the sagittal plane, grip strength, and modified Green O'Brien score both at 3 and 6 months postsurgery, but poorer results for the range of motion in forearm rotation. Regarding DASH score and modified Green O'Brien score, we reached similar results in the DASH score, but better in the Green O'Brien score at 3 and 6 months after surgery. As in the study by Osada et al, patients were taught only wrist exercises, but there was no controlled regular physiotherapy. Patient compliance of keeping to the recommended exercise program was also not monitored. This could possibly have influenced the better outcome in range of motion and grip strength in our study.
The IM group also wore a removable splint; therefore, a continuous monitoring of wrist IM was not possible. Lozano-Calderón also included 12/30 Type A, 1/30 Type B, and $17 / 30$ Type $C$ fractures. In our study, we included 1/15 Type A, 1/15 Type B, and with $13 / 15$ more Type C fractures ( 87 vs. $57 \%$ ). This type of fracture more frequently affects the distal radio ulnar joint. Therefore, the poorer results in the forearm rotation can be explained.

Before interpreting this study, there are some limitations that should be kept in mind. First, due to its design as a pilot trial, only 30 patients were included. Therefore, further studies with larger populations would be necessary to confirm our findings. Second, our study included more Type C fractures than in any other study which may have had an impact on our final outcome, but we did not perform standard CT scans after surgery. So the definitive impact of a malunion of the distal radioulnar joint or lunate fossa can only be hypothesized. We also included patients with a fracture of the processus styloideus ulnae in the study but did not analyze the differences in functional outcome. Further studies should consider this. But as the VAS score at 1 year after 


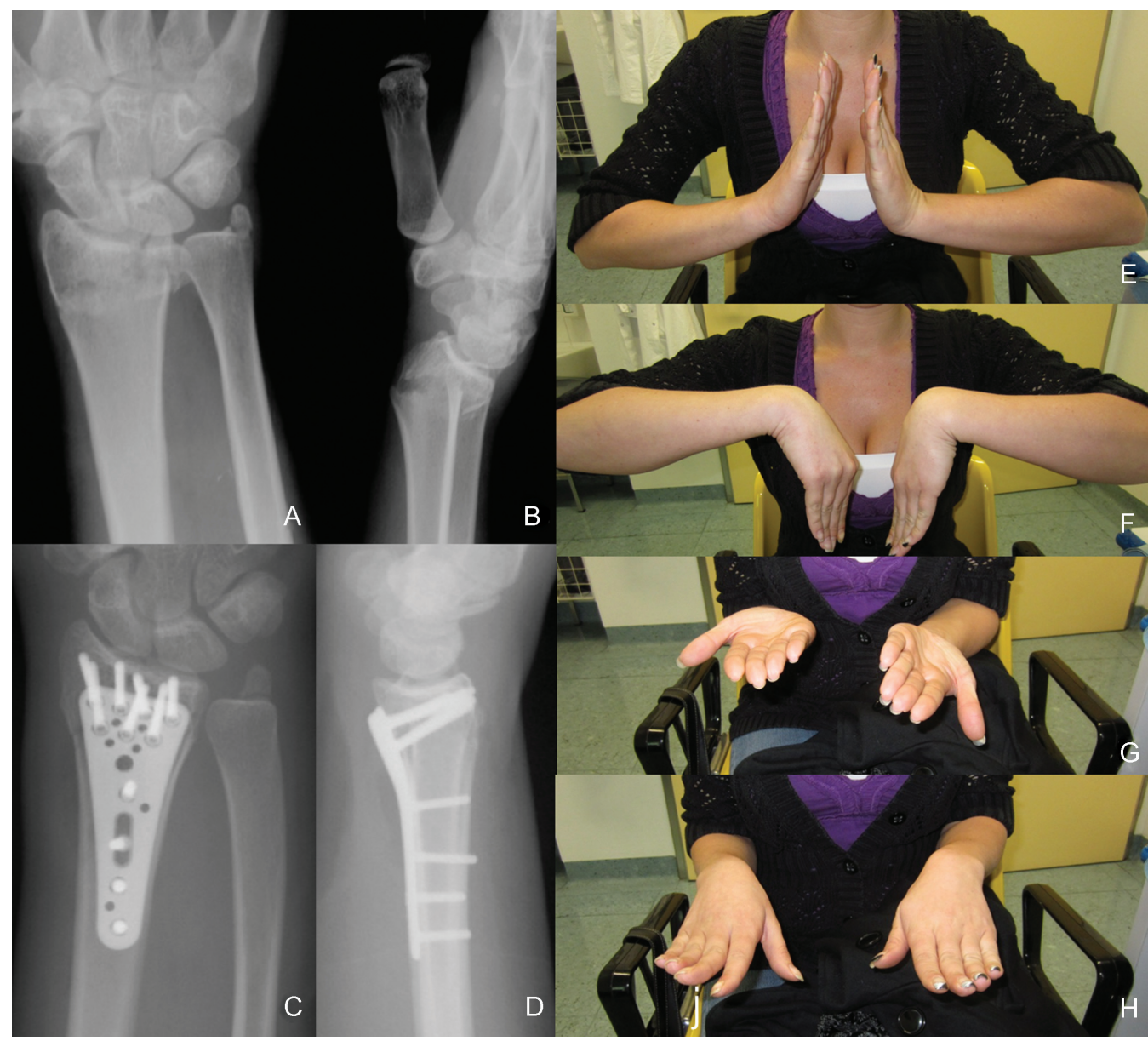

Fig. 4 A 29-year-old woman: (A, B) Type C1 distal radius fracture before reduction; (C, D) Distal radius fracture stabilized by volar locking plate; $(\mathrm{E}-\mathrm{H})$ clinical results 6 weeks after surgery.

Table 3 Radiological outcomes (mean \pm SD)

\begin{tabular}{|c|c|c|c|}
\hline & \multicolumn{2}{|l|}{ Study group } & \multirow[t]{2}{*}{ p-Value } \\
\hline & Early Mobilization $(n=15)$ & Immobilization $(n=13)$ & \\
\hline \multicolumn{4}{|l|}{ Palmar tilt (degree) } \\
\hline Before surgery/reduction & $-29.22 \pm 18.86$ & $-25.1 \pm 16.33$ & 0.57 \\
\hline Postsurgery & $5.81 \pm 3.43$ & $3.08 \pm 4.14$ & 0.06 \\
\hline Last follow-up examination & $5.02 \pm 3.05$ & $1.56 \pm 6.38$ & 0.09 \\
\hline Loss of reduction & $0.79 \pm 1.90$ & $1.52 \pm 3.13$ & 0.12 \\
\hline \multicolumn{4}{|l|}{ Radial inclination (degree) } \\
\hline Before surgery/reduction & $13.31 \pm 18.17$ & $14.19 \pm 10.84$ & 0.57 \\
\hline Postsurgery & $21.91 \pm 4.74$ & $19.63 \pm 5.19$ & 0.26 \\
\hline Last follow-up examination & $21.71 \pm 4.85$ & $19.46 \pm 5.24$ & 0.21 \\
\hline Loss of reduction & $0.2 \pm 0.53$ & $0.17 \pm 0.61$ & 0.28 \\
\hline \multicolumn{4}{|l|}{ Ulnar variance $(\mathrm{mm})$} \\
\hline Postsurgery & $0.00 \pm 0.00$ & $0.00 \pm 0.00$ & 1.00 \\
\hline Last follow-up examination & $0.00 \pm 0.00$ & $0.00 \pm 0.00$ & 1.00 \\
\hline Loss of reduction & $0.00 \pm 0.00$ & $0.00 \pm 0.00$ & 1.00 \\
\hline
\end{tabular}


surgery was low and all patients regained nearly full range of motion, the impact of an additional fracture of the processus styloideus ulnae may only be low. Using functional treatment without casting enables the patient to do daily activities more easily, as wrist movement in flexion and extension is not restricted. Therefore, we should have included a score whereby quality of life during the study was measured. Further research ought to consider this issue. In contrast to other studies before investigating EM, both groups received supervised physiotherapy. Thus, complying with the exercise program was ensured in our study.

The aforementioned data strongly supports that direct postoperative mobilization of DRFs stabilized by volar locking plate is reliable (no loss of reduction) and also promotes improved wrist function. In this study, a better range of motion in the sagittal plane up to 6 months, in the frontal plane up to 9 weeks, in forearm rotation up to 6 weeks, and in grip strength up to 6 months was demonstrated. Functional scores were also better up to 6 weeks postsurgery. An additional finding showed all patients in the EM group regained full range of motion when compared with the uninjured side at 6 months postsurgery. No differences regarding loss of reduction were observed.

Ethical Approval

Institutional review board approval was obtained for this study.

Location of the Study

This study was performed at the AUVA Trauma Hospital Lorenz Böhler - European Hand Trauma Center, Vienna, Austria.

Funding

None.

\section{Conflict of Interest}

None.

\section{References}

1 Singer BR, McLauchlan GJ, Robinson CM, Christie J. Epidemiology of fractures in 15,000 adults: the influence of age and gender. J Bone Joint Surg Br 1998;80(2):243-248

2 Court-Brown CM, Caesar B. Epidemiology of adult fractures: a review. Injury 2006;37(8):691-697

3 Zong SL, Kan SL, Su LX, Wang B. Meta-analysis for dorsally displaced distal radius fracture fixation: volar locking plate versus percutaneous Kirschner wires. J Orthop Surg 2015;10:108. Doi: 10.1186/s13018-015-0252-2

4 Wei DH, Raizman NM, Bottino CJ, Jobin CM, Strauch RJ, Rosenwasser MP. Unstable distal radial fractures treated with external fixation, a radial column plate, or a volar plate. A prospective randomized trial. J Bone Joint Surg Am 2009;91(7):1568-1577

5 Jupiter JB, Lipton $\mathrm{H}$. The operative treatment of intraarticular fractures of the distal radius. Clin Orthop Relat Res 1993;(292): 48-61
6 Palmer AK. Fractures of the distal radius. In: Green DP, Hotchkiss RN, eds. Operative Hand Surgery. Vol. 1, 3rd ed. New York: Churchill Livingstone; 1993:929-971

7 Jupiter JB. Fractures of the distal end of the radius. J Bone Joint Surg Am 1991;73(3):461-469

8 Klein SM, Prantl L, Koller M, et al. Evidence based postoperative treatment of distal radius fractures following internal locking plate fixation. Acta Chir Orthop Traumatol Cech 2015;82(1):33-40

9 Lichtman DM, Bindra RR, Boyer MI, et al; American Academy of Orthopaedic Surgeons. American Academy of Orthopaedic Surgeons clinical practice guideline on: the treatment of distal radius fractures. J Bone Joint Surg Am 2011;93(8):775-778

10 Leitlinie der deutschen Gesellscahft für Unfallchirrugie. Distale Speichenfraktur; AWMF-Registernummer: 012-015. Available at: http://www.awmf.org/uploads/tx_szleitlinien/012-0151_S2e_Distale_Radiusfraktur_2015-02.pdf2015

11 Lozano-Calderón SA, Souer S, Mudgal C, Jupiter JB, Ring D. Wrist mobilization following volar plate fixation of fractures of the distal part of the radius. J Bone Joint Surg Am 2008;90(6):1297-1304

12 Beaton DE, Wright JG, Katz JN; Upper Extremity Collaborative Group. Development of the QuickDASH: comparison of three item-reduction approaches. J Bone Joint Surg Am 2005;87(5): 1038-1046

13 Hemelaers L, Angst F, Drerup S, Simmen BR, Wood-Dauphinee S. Reliability and validity of the German version of "the Patient-rated Wrist Evaluation (PRWE)" as an outcome measure of wrist pain and disability in patients with acute distal radius fractures. J Hand Ther 2008;21(4):366-376

14 Cooney WP, Bussey R, Dobyns JH, Linscheid RL. Difficult wrist fractures. Perilunate fracture-dislocations of the wrist. Clin Orthop Relat Res 1987;X(214):136-147

15 Müller ME, Nazarian S, Koch P, et al. Comprehensive Classification of Fractures of Long Bones. Berlin, Germany: Springer; 1990

16 Schmitt R, Pommersberger KJ. Karpale Funktion und Morphometerie. In: Schmitt R, Lanz U, eds. Bildgebende Diagnostik der Hand. 3rd ed. Germany: Thieme; 2014:184-197

17 Arora R, Lutz M, Deml C, Krappinger D, Haug L, Gabl M. A prospective randomized trial comparing nonoperative treatment with volar locking plate fixation for displaced and unstable distal radial fractures in patients sixty-five years of age and older. J Bone Joint Surg Am 2011;93(23):2146-2153

18 Rueger JM, Hartel MJ, Ruecker AH, Hoffmann M. Fractures of the distal radius [in German]. Unfallchirurg 2014;117(11):1025-1034, quiz 1035-1036

19 Rueger M, Linhart W, Sommerfeldt DW. Differentialindikation zur Behandlung der distalen Radiusfraktur. Trauma und Berufskrankheit 1998;1(1):6-14

20 Wilcke MKT, Hammarberg H, Adolphson PY. Epidemiology and changed surgical treatment methods for fractures of the distal radius: a registry analysis of 42,583 patients in Stockholm County, Sweden, 2004-2010. Acta Orthop 2013;84(3):292-296

21 Figl M, Weninger P, Jurkowitsch J, Hofbauer M, Schauer J, Leixnering M. Unstable distal radius fractures in the elderly patient-volar fixed-angle plate osteosynthesis prevents secondary loss of reduction. J Trauma 2010;68(4):992-998

22 Koh S, Morris RP, Patterson RM, Kearney JP, Buford WLJr, Viegas SF. Volar fixation for dorsally angulated extra-articular fractures of the distal radius: a biomechanical study. J Hand Surg Am 2006; 31(5):771-779

23 Colles A. On the fracture of the carpal extremity of the radius. Edinb Med Surg J. 1814;10:181. Clin Orthop Relat Res 2006;445:5-7

24 MacDermid JC, Roth JH, Richards RS. Pain and disability reported in the year following a distal radius fracture: a cohort study. BMC Musculoskelet Disord 2003;4:24. Doi: 10.1186/1471-2474-4-24

25 Kenwright J, Richardson JB, Goodship AE, et al. Effect of controlled axial micromovement on healing of tibial fractures. Lancet 1986; 2(8517):1185-1187 
112 Early Rehabilitation of Distal Radius Fractures Stabilized by Volar Locking Plate Quadlbauer et al.

26 Osada D, Kamei S, Masuzaki K, Takai M, Kameda M, Tamai K. Prospective study of distal radius fractures treated with a volar locking plate system. J Hand Surg Am 2008;33(5):691-700

27 Wright TW, Horodyski M, Smith DW. Functional outcome of unstable distal radius fractures: ORIF with a volar fixed-angle tine plate versus external fixation. J Hand Surg Am 2005;30(2):289-299

28 Osada D, Fujita S, Tamai K, Iwamoto A, Tomizawa K, Saotome K. Biomechanics in uniaxial compression of three distal radius volar plates. J Hand Surg Am 2004;29(3):446-451

29 Osada D, Viegas SF, Shah MA, Morris RP, Patterson RM. Comparison of different distal radius dorsal and volar fracture fixation plates: a biomechanical study. J Hand Surg Am 2003; 28(1):94-104

30 Handoll $\mathrm{HH}$, Elliott J. Rehabilitation for distal radial fractures in adults. Cochrane Database Syst Rev 2015;(9):CD003324. Doi: 10.1002/14651858.CD003324.pub3

31 Handoll HH, Madhok R, Howe TE. Rehabilitation for distal radial fractures in adults. Cochrane Database Syst Rev 2006;(3): CD003324. Doi: 10.1002/14651858.CD003324.pub2

32 Chung KC, Watt AJ, Kotsis SV, Margaliot Z, Haase SC, Kim HM. Treatment of unstable distal radial fractures with the volar locking plating system. J Bone Joint Surg Am 2006;88(12):2687-2694 